\title{
PROYECCIÓN EXTERIOR, HISPANOAMERICANISMO Y REGENERACIÓN NACIONAL EN LA PENÍNSULA IBÉRICA EN EL SIGLO XIX
}

\author{
César Rina Simón \\ Universidade de Lisboa
}

$\mathrm{E}_{\text {ria transnacional, atendiendo al tráfico de ideas, a las rela- }}^{\mathrm{n} \text { este estudio nos proponemos hacer un ejeicio de histo- }}$ ciones de grupos sociales y a las proyecciones internacionalistas e hispanoamericanas de las élites ibéricas dentro de una lógica que desafía el paradigma espaciotemporal de los estados-nación. Entendemos por prácticas e imaginarios transnacionales aquellos que trascienden a los agentes oficiales del Estado y cuyo análisis conlleva la ruptura del planteamiento historiográfico estado-céntrico. Las identidades en el mundo contemporáneo se construyeron también a partir de ideales cosmopolitas o imperialistas y, por abajo, de narrativas regionales y locales, ${ }^{1} \mathrm{y}$ se nutrieron de la mirada exterior, de la visión estereotipada de los viajeros, de las migraciones, los exilios y la actividad diplomática. La historia de los nacionalismos es, por tanto, la de un movimiento, una suma, un debate, y no la de una formación

Fecha de recepción: 22 de enero de 2016

Fecha de aceptación: 5 de febrero de 2017

${ }^{1}$ NúÑEZ SeIXAS, “Nation-Building and Regional Integration”. 
política o ideológica conclusa. ${ }^{2}$ Surgieron en un horizonte de desarraigo de las comunidades, ante la caída de los grandes principios que articulaban el mundo y se formularon junto a la noción de decadencia, que llamaba al conjunto de la ciudadanía a renacionalizar ante el sentimiento de pérdida. De esta forma, a principios del siglo xIx, las comunidades políticas imperiales o postimperiales iniciaron su transformación en estados nacionales a partir de una historia que los legitimaba para participar como agentes soberanos. ${ }^{3}$

Las dinastías de Portugal y de España comenzaron el siglo XIX sumidas en una profunda crisis institucional. En 1807, las tropas napoleónicas entraron en la península ibérica por el Tratado de Fontainebleau y motivaron la marcha de la corte portuguesa a Brasil y la reclusión voluntaria de los Borbones en Francia, sustituidos por un sistema monárquico regido por el hermano de Napoleón, José Bonaparte. Reinos que, tres siglos antes, en el Tratado de Tordesillas, se habían repartido los dominios del continente americano y habían tenido un papel protagonista en la escena internacional, en las primeras décadas del siglo XIX vieron mermado significativamente su imperio colonial y perdieron la soberanía sobre la Península.

A la decadencia política de estas potencias habría que sumarle la "leyenda negra", relacionada con el "efecto Montesquieu" o con la influencia aún más relevante de autores como Raynal, un conjunto de narrativas racionalistas e ilustradas por las cuales España y Portugal se convirtieron en el paradigma europeo de espacios fronterizos entre Oriente y Occidente, territorios incapacitados para entrar en la dinámica del progreso y dominados por la intransigencia religiosa y la violencia. ${ }^{4} \mathrm{El}$ mito de una Europa septentrional ilustrada frente a una meridional

${ }^{2}$ Guardia y Pan-Montojo, "Reflexiones sobre una historia transnacional"; Silmal, "Una perspectiva”.

3 Matos, “¿Cómo convivir con la pérdida?”

${ }^{4}$ Villaverde y Castilla (dirs.), La sombra; Bourdieu, "Le Nord et le Midi”. 
orientalizada y bárbara influyó activamente en el pensamiento político peninsular, aceptando buena parte de los liberales sus principios constitutivos. La leyenda negra de una Península cainita, intransigente y religiosa ahondó en la toma de conciencia de la crisis peninsular, mito referencial en la construcción del estado-nación.

Un último elemento a tener en cuenta en la entrada del ochocientos de las coronas de Portugal y España fue la progresiva independencia de sus colonias americanas que, además de las repercusiones socioeconómicas, supuso un aldabonazo más en la conciencia decadentista peninsular y en la articulación de proyectos expansivos que la redimieran. Este proceso coincidió cronológicamente con una dinámica internacional caracterizada por condicionar el principio de nacionalidad a la capacidad de construir imperios coloniales.

La historiografía peninsular ha incidido en las crisis de 1890 y 1898 como acontecimientos formativos de la noción de decadencia y de las expectativas expansionistas y americanistas, con algunas excepciones reseñables. ${ }^{5}$ En 1890, el gobierno luso tuvo que abandonar su proyecto imperialista de conectar Angola y Mozambique ante el ultimátum del ejecutivo inglés, que veía peligrar su deseo de conectar El Cairo con El Cabo. En 1898, Cuba, Puerto Rico y Filipinas lograron la independencia de la metrópoli por la presión política y armada de los isleños y el empuje del expansionismo de Estados Unidos. ${ }^{6}$ Ambos acontecimientos despertaron una intensa solidaridad peninsular y avivaron las proyecciones iberistas de construcción de un estado peninsular que hiciera frente a las amenazas internacionales. ${ }^{7}$ Sin embargo, sin restar importancia a las repercusiones que tuvieron estas crisis en la evolución de las culturas políticas peninsulares,

${ }^{5}$ Como las de Litvak, España 1900; Pires, A ideia de decadência.

${ }^{6}$ Previamente, España había sufrido reveses coloniales en Filipinas en 1877 y con Alemania en las islas Carolinas en 1885.

7 Vázquez Cuesta, A Espanha ante o "ultimátum". 
en las siguientes páginas trataremos de incidir en cómo los conceptos de decadencia y regeneración, y las proyecciones americanistas, estuvieron muy extendidos en el siglo xIx y sirvieron de estímulo y argumento tanto para un nacionalismo expansionista como para un cosmopolitismo de corte democrático y federal. ${ }^{8}$ Estaríamos, por tanto, ante un tópico historiográfico planteado desde la perspectiva adanista de la generación del 98, la primera en la que podemos utilizar el término de "intelectuales" en las dimensiones de Zola en J'Accuse, y por la tendencia contemporaneísta de focalizar los estudios en el siglo xx. El análisis de los discursos americanistas, su activo asociacionismo y su plasmación simbólica en celebraciones públicas - como las del centenario de la muerte de Camões en 1880 y el IV centenario del descubrimiento de América en 1892-, señalan una presencia constante de estas proyecciones y anhelos en las narrativas del ochocientos. ${ }^{9}$ De hecho, antes del desastre de 1898 ya habían sido publicadas o escritas la mayoría de las obras que la historiografía ha considerado canónicas y sintomáticas de la crisis colonial. ${ }^{10}$ Para el caso portugués, la noción de decadencia era central en la ensayística sobre el ser nacional, especialmente en la geração

${ }^{8}$ Como nos recuerda García Cárcel, La herencia del pasado, p. 592, la articulación del discurso de la decadencia y del fracaso español se remontaría al siglo xvi y los tratados de los arbitristas. Para la relación entre decadencia y americanismo en el momento de las independencias remitimos a EASTMAN, "America has escaped".

9 Véase Marcilhacy, Raza hispana; Bernabeu Albert, 1892. Un análisis comparativo de las conmemoraciones en las repúblicas americanas en RODRíGUEz, Celebración de la raza.

${ }_{10}$ Nos referimos a Estudios sobre el engrandecimiento y la decadencia de España, de Pedregal y Cañedo en 1878; L'Espagne telle qu'elle est, de Valentí Almirall en 1886; La decadencia de la civilización de España, de Pompeyo Gener en 1887; Los males de la patria, de Lucas Mallada en 1890; En torno al casticismo, de Miguel de Unamuno en 1895, Idearium español, de Ángel Ganivet en 1896; El problema nacional, de Macías Picavea en 1899. En ellas, los males de la nación tenían su origen en la intransigencia religiosa, el absolutismo monárquico y el centralismo. 
de 1870. En este sentido, conviene no olvidar que los estadosnación se construyeron sobre un programa de acción exterior, no sólo desde una introspección historicista. La capacidad de actuar en la escena internacional, de influir sobre otras naciones o de "civilizar" otros pueblos fueron elementos formativos de las narrativas nacionales en la época de los imperialismos. ${ }^{11}$

ENTRE LA NOSTALGIA IMPERIAL

Y EL COLONIALISMO EUROPEO ${ }^{12}$

Si tomamos como referencia la articulación teórica del tiempo histórico planteada por Reinhart Koselleck, no cabe duda de que la irrupción de las narrativas nacionales en la modernidad estuvo protagonizada por la tensión entre el campo de la experiencia y el horizonte de expectativas. Estos dos elementos constituyeron la lógica argumentativa de las culturas políticas a partir de una narración imaginada que conectaba el pasado y el presente de la nación y la proyectaba hacia un futuro determinado. ${ }^{13} \mathrm{El}$ pensamiento historiográfico del siglo xix basculó, dentro de los márgenes de los imaginarios nacionalistas, entre la búsqueda de un pasado idealizado, recreado como expectativa de un presente en crisis, desnacionalizado, y la proyección hacia un futuro positivista de regeneración, que en el caso español y portugués estuvo protagonizado por el binomio decadencia-redención. ${ }^{14}$

\footnotetext{
${ }^{11}$ Los nacionalismos articularon una teoría territorial homogénea y definida históricamente, pero también un imperialismo que medía el prestigio nacional a partir de la capacidad de extenderse a otros pueblos y dominarlos por la capacidad de exportar la civilización, como sería el caso de los descubrimientos. Matos, Consciência histórica, pp. 53-71.

12 Partimos en este epígrafe de Blanco, "Imperial Nostalgia”.

${ }^{13}$ Koselleck, historia/Historia. Lowenthal, El pasado, ha señalado la escisión del tiempo en las sociedades modernas. Un análisis desde la perspectiva americana en Zermeño Padilla, "Historia, experiencia y modernidad" y Pérez Vejo, "La construcción de las naciones”.

${ }^{14}$ Fuentes, "Regeneración”.
} 
El continente americano jugó un papel central en este eje pasado-futuro, tanto en las culturas políticas peninsulares como en las narrativas historiográficas. Una América como proyección, estímulo y pretexto, imaginada y recreada desde la Península, pero nunca como práxis política. ${ }^{15} \mathrm{La}$ mirada al pasado se articuló en dos direcciones principales - aunque poliédricas - en relación con el americanismo. Por un lado, como manifestación presente de un tiempo a emular, de una grandeza, constatación de las potencialidades constitutivas de la identidad española y portuguesa y de sus hazañas pasadas. En esta línea, en 1840 señalaba Eugenio Tapia: "América recibió entonces por primera vez la moral de una religión sublime, conoció la escritura y demás artes de la civilización, y debió a los monarcas españoles un código de leyes justas, que han merecido las alabanzas de todos los escritores imparciales" ${ }^{16}$ Por otro, como nostalgia de lo perdido, lamento por lo que pudo ser y no fue. Así mismo, las expectativas americanistas abarcaron múltiples fórmulas regeneracionistas, desde una esfera imperialista de emulación de otras potencias, hasta otra más civilizacional, de confederación de naciones con afinidades culturales, lingüísticas, espirituales e históricas, siempre desde el núcleo común de la nacionalización. ${ }^{17}$

De esta forma, el tránsito de la memoria nostálgica imperial al programa colonial moderno dependió de los contextos políticos y de los autores que la articularon, una actitud ambivalente y poliédrica en la mayoría de los casos que no puede llevarnos a obviar la importancia de las expectativas imperialistas en la

\footnotetext{
${ }^{15}$ Sepúlveda, El sueño de la Madre Patria; Feros, "Spain and America”.

${ }^{16}$ TAPIA, Historia de la civilización española.

17 Álvarez Junco, Mater Dolorosa, ha señalado que el concepto nación pesó más que el de imperio en los imaginarios patrióticos españoles. Esta visión secundaria se explicaría por la reciente pérdida colonial, que llevó a los historiadores a focalizar su atención en las victorias. Sin embargo, como ha señalado Pérez Vejo, España imaginada, en la nacionalización española sí encontramos abundantes referencias al imperio americano. Estas proyecciones fueron transversales a las culturas políticas progresistas, moderadas y reaccionarias.
} 
articulación de los imaginarios nacionales en España y Portugal. Especialmente en dos líneas complementarias: una nación espiritual proyectada hacia el Atlántico y una memoria positivista que determinaba la nacionalidad a partir de marcadores históricos. ${ }^{18}$ La nostalgia por un tiempo perdido, más plenamente nacional, fue una pieza clave en la articulación de las narrativas nacionalistas. De hecho, en los casos español y portugués, la noción de decadencia o crisis ocupó un espacio central, bien desde una óptica apologética, bien desde el criticismo, pero en ambos casos desde la búsqueda de explicaciones al fracaso y del planteamiento de propuestas regeneracionistas. ${ }^{19} \mathrm{El}$ análisis historiográfico ha constatado cómo la articulación de narrativas nacionales no sólo giró en torno al recuerdo de acontecimientos fundacionales o a una caracterología propia. Más bien, la identificación con un ser doliente, en decadencia, alentó las proyecciones redencionistas y los esfuerzos por engrandecerse, por sobrevivir en el conjunto de las naciones y regenerarse. De esta forma, las historias nacionales no sólo se nutrieron de discursos centrípetos en torno al alma nacional, sino que se proyectaron en un cúmulo de anhelos cosmopolitas, federalistas o imperialistas que abarcarían, con múltiples mecanismos, otros territorios ajenos a la nación. ${ }^{20}$

${ }_{18}$ Acerca de la importancia de la mitología imperial en el nacionalismo español véase Blanco, Cultura y conciencia. Encontramos un ejemplo en la política imperialista de la Unión Liberal en México y Marruecos. Para el nacionalismo portugués, Matos, "Patria, nación, nacionalización".

${ }^{19}$ López-Vela, "De Numancia a Zaragoza”.

${ }^{20}$ En el horizonte americano además compartían una raza, un espíritu o una civilización. El concepto de raza no podemos entenderlo en el caso peninsular desde el darwinismo social o el racismo de Gobineau, pues su trayectoria se vincula al pensamiento progresista de mediados del siglo xIx. Raza haría referencia a una cultura y no a una diferenciación biológica. Valera, Castelar o Moret se refirieron a ella sin connotaciones raciales. Intervención de Segismundo Moret en el Congreso de los Diputados el 18 de noviembre de 1900, citada en Unión Ibero-Americana (nov. 1900): "La Raza es una vida común, es lazo de recuerdos, de sentimientos, de aspiraciones, de ideales de porvenir". Labra la denominaría "intimidad hispanoamericana" en El problema hispano-americano. Véase 
En este sentido, en el interés peninsular por extenderse y representarse en América nos encontramos ante una fórmula de representación del otro como continuidad nacional, proyectada hacia territorios sobre los que se vindicaba un derecho de paternidad:

España ha realizado, providencialmente sin duda, la obra más grande que registra la historia: el descubrimiento, conquista y civilización de América. Solamente la raza hispana, esencialmente creadora, pudo llevar a cabo epopeya tan gloriosa, debido a la fe y amor de nuestros antepasados, porque una y otro han sido el fundamento de nuestras glorias. ${ }^{21}$

La búsqueda del continente americano surgió pareja a las independencias, con repuntes sucesivos a lo largo del ochocientos relacionados con la conciencia de crisis. ${ }^{22} \mathrm{El}$ proceso ha sido conceptualizado acertadamente por Pérez Vejo, al referirse al hispanoamericanismo como imperialismo de sustitución, mecanismo ideológico que articuló un proyecto espiritual y civilizacional ante la incapacidad estatal de construir un imperio territorial.

\section{LA IDENTIDAD DOLIENTE. LAS CAUSAS DE LA DECADENCIA}

La noción de decadencia fue aceptada por las élites intelectuales ibéricas como uno de los mitos constitutivos del presente

Goode, Impurity of Blood. Se convertiría en término racial entrado el siglo xx, con la formulación de los panhispanismos. Es fundamental diferenciar los términos hispanoamericanismo, hispanismo y panhispanismo. Una aclaración en Sepúlveda, El sueño de la Madre Patria, pp. 91 y ss.

${ }^{21}$ Gutiérrez Solana, La gran familia, pp. 6-7.

22 Matos, "Linguagem do patriotismo". Marcilhacy, en "América como vector de regeneración” señala el triunfo del hispanoamericanismo en la Restauración borbónica no por el peso de las narrativas culturalistas o historicistas, sino por el contenido regeneracionista que acarreaba. 
peninsular y de la caracterología diferenciada de sus pueblos. ${ }^{23}$ Liberales, conservadores y católicos coincidieron en el diagnóstico decadentista, no así en las causas que la propiciaban. Para progresistas como Antonio Ferrer del Río, la decadencia comenzó con el fracaso de la revuelta de los comuneros de Castilla y la entrada en la Península de una dinastía extranjera, la de los Habsburgo, que impuso un modelo absolutista ajeno a las prácticas comunitarias peninsulares. ${ }^{24}$ Por ello, planteaba una liberalización política que permitiera a España salir del ostracismo. En 1852, Adolfo de Castro abordó la temática alertando que reconocer la decadencia era un acto de patriotismo y de amor por su país. En su programa, generalizado para el liberalismo progresista español, la decadencia era el resultado de la intolerancia, de la Inquisición, de la pérdida de principios predemocráticos como el municipalismo, de la degeneración de la monarquía y de la intransigencia religiosa. Es decir, de la asunción de los presupuestos de la leyenda negra, cuyas consecuencias se extenderían a América. Estos elementos justificarían las independencias de las repúblicas americanas: "Si España se vanagloria de Hernán Cortés [...], América se vanagloria de su libertador Bolívar". ${ }^{25}$ Para Castro, el descubrimiento de las Indias perjudicó a España por la despoblación y por la "sed de oro", ya que se abandonó en gran medida el trabajo de la tierra y las artes en la Península. La política española en América "no fue otra cosa que la continuación exagerada de lo mismo que se

\footnotetext{
${ }^{23}$ Influyó la obra The History of the Decline and Fall of the Roman Empire, publicada en 1766 por Edward Gibbon, donde proponía la articulación del pasado en una serie de fases protagonizadas por sucesivos auges y caídas de las civilizaciones.

${ }^{24}$ Ferrer del Río, Decadencia de España. Esta narrativa fue común en el liberalismo español, finalizando la edad de oro con el reinado de los Reyes Católicos. Véase Álvarez Junco, Mater Dolorosa; Rina Simón, “Discursos de alteridad".

${ }^{25}$ CASTro, Examen filosófico, p. 157.
} 
practicaba en la Península”. ${ }^{26}$ Aquella "horrible conquista" sólo fue cuestionada por "apóstoles de la humanidad" como Bartolomé de Las Casas; sin embargo, en España se conmemoraban más las gestas de los conquistadores. Castro llegaba al punto de ensalzar las independencias americanas, "los pueblos no eligen el instante de cobrar sus libertades [...]: cuando se les presenta, suelen aprovecharlo, y ello no hace más que seguir el orden de todos los acontecimientos humanos". ${ }^{27}$ La decadencia seguía vigente a mediados del siglo xIx por la falta de libertad política, de imprenta, comercial y religiosa.

En la coyuntura unionista italiana y alemana, Fernando Garrido, inspirado en Mazzini, publicó La regeneración de España, un proyecto de unión ibérica en el que conceptualizaba la noción de decadencia y planteaba una reforma administrativa, democrática y territorial de los pueblos peninsulares, constituyéndose como una de las primeras obras del ochocientos que versaban sobre la idea nacionalizadora de regeneración. ${ }^{28}$

Cánovas del Castillo, desde la óptica del conservadurismo, situaba la problemática en los Austrias Menores, estableciendo una clara analogía entre el siglo xvi y el xix español. La decadencia había sido o bien ignorada por los autores nacionales, o bien tergiversada por los extranjeros. Esta carencia justificaba su explicación en pretérito, ya que la historia contemporánea "es

\footnotetext{
${ }^{26}$ Castro, Examen filosófico, p. 142.

${ }^{27}$ Castro, Examen filosófico, p. 142. El liberalismo hispano presentó múltiples interpretaciones de la independencia, desde su justificación ante la dominación española hasta el lamento por la tierra y la civilización compartida. Mendíbil, Cuadro Histórico, p. iv: "Mi opinión particular en cuanto a la independencia de nuestros hermanos de América desde que en la Península se restablecieron las instituciones [...] del poder absoluto, siempre ha sido afirmativa a favor de la emancipación, por el íntimo convencimiento de que, aplicadas a la América las leyes de la libertad civil [...], la consecuencia forzosa tenía que ser la separación, aunque conservando ciertos lazos de fraternidad y recíproco provecho".

${ }^{28}$ GARRIDO, La regeneración de España.
} 
siempre espinosa y casi pudiera decirse imposible". ${ }^{29}$ Cánovas, sin embargo, no relacionaba la decadencia con la independencia de las colonias americanas, sino con el alejamiento del espíritu nacional de sus dos almas constitutivas que la unían en volksgeist e historia, no en voluntad renaniana: la monarquía y el catolicismo. Una de las vías de regeneración pasaba por participar del movimiento imperialista de las grandes potencias en África e Hispanoamérica. ${ }^{30}$

Para el caso portugués, encontramos un ejemplo temprano de conceptualización de la crisis en la obra del escritor romántico Almeida Garrett. El autor reflexionaba, hacia 1830, sobre la debilidad portuguesa tras la pérdida del imperio brasileño y la coyuntura internacional de formación de grandes estados. Portugal había entrado en el siglo en franca decadencia y viendo peligrar su autonomía política, no sólo fruto de la emancipación americana sino también del periodo de incertidumbre abierto tras la revolución francesa. El país necesitaba, según Garrett, un nuevo estímulo político para superar el estado de postración. El cambio de hegemonías había convertido al movimiento libertador americano en el proyecto político regeneracionista a emular, en especial el de Estados Unidos. ${ }^{31}$ El foco de irradiación liberal había basculado de Europa hacia América. ${ }^{32}$ Las independencias fueron la respuesta natural de los oprimidos contra los opresores y se habían convertido en agentes de irradiación de liberalismo: “QQué ejemplar, qué espejo para las otras naciones del globo!”. ${ }^{33}$

29 Cánovas del Castillo, Historia de la decadencia, p. 2.

30 Cánovas del Castillo, Discurso sobre la nación.

31 Almeida Garrett, Portugal na balança, pp. 36 y ss. Era muy crítico con la conquista, hecha por los "parasytos da Europa”, y defendía la independencia justa de las colonias en combate contra el despotismo europeo.

32 Almeida Garrett, Portugal na balança, p. 58.

33 Almeida Garrett, Portugal na balança, p. 116, si bien reconocía que América y la península ibérica estaban ligadas por intereses comunes de sangre, lengua o religión, “siendo físicamente las más separadas por su situación geográfica, son de todas las que más unidas están”. 
La clave de la obra de Garrett fue que apuntó como una de las posibles vías para situar a Portugal en la balanza europea su unión con España. Dicha unión no era deseable, pero sería inevitable si la imponían Francia o Inglaterra y si persistía el absolutismo en la Península y el hartazgo luso a la dependencia inglesa. En cualquier caso, la nueva nación no sería ni portuguesa, ni catalana, ni castellana, sino ibérica. La pervivencia de Portugal pasaba por extender por el país instituciones representativas, dinastías aceptadas por la nación y leyes. En caso contrario, no podría mantener su independencia. "El mejor camino de invasión castellana de Madrid a Lisboa es un gobierno flaco, tiránico y antinacional". ${ }^{34}$

En línea con el pensamiento federal proudhoniano y el republicanismo, y al calor de la Revolución Gloriosa y sus anhelos de regeneración democrática de la Península, Antero de Quental dictó en 1871, en el Casino Lisbonense, una conferencia que explicaba la decadencia ibérica. El escritor, imbuido del compromiso político propio de la geração de 70 , llevaba los orígenes de la decadencia al siglo xvir al avance del absolutismo y del centralismo a costa de las tradiciones "democráticas", "federales" y "municipalistas" del medievo peninsular. A ello habría que sumarle el desgaste económico provocado por el mantenimiento de los imperios ultramarinos y la intolerancia religiosa. La vía regeneracionista pasaba por el federalismo y el municipalismo, ideas que había tratado desde la historiografía Alexandre Herculano y desde el compromiso político el republicano Henriques Nogueira. ${ }^{35}$

A mediados del siglo xix, seguía vigente entre los horizontes culturales europeos el mito romántico ibérico, la identificación caracterológica de los pueblos peninsulares en oposición a los europeos. ${ }^{36}$ Una de las obras que más contribuyó a asentar el mito historiográfico de la leyenda negra en la Península fue

\footnotetext{
34 Almeida Garrett, Portugal na balança, p. 229. La obra se publicó en pleno conflicto miguelista entre absolutistas y liberales.

35 Quental, Causas da decadência.

36 Remitimos a Andreu Miralles, El descubrimiento de España.
} 
History of Civilization in England, de Henry Thomas Buckle. Publicada en 1861, dedicaba un capítulo a la civilización española en clave dicotómica de norte-progreso, sur-atraso, incidiendo en su carácter dominado por el fundamentalismo religioso y su incapacidad para el comercio y para liderar progresos. Esto la condenaba a la servidumbre frente a otras civilizaciones, como la anglosajona o la germánica, convocadas al liderazgo del individualismo y las libertades y no al colectivismo y la sumisión a los césares. Buckle aplicaba la noción de progreso y el darwinismo social al devenir de las civilizaciones para explicar la evolución de las hegemonías, en línea con el pensamiento ilustrado y orientalizante que interpretó lo español en términos de atraso. ${ }^{37}$

Una de las respuestas más contundentes a esta obra fue la História da Cilivização Ibérica de Oliveira Martins, publicada en 1879. Martins retomaba el concepto de civilización de Guizot y Macauly para articular una respuesta civilizacional ibérica desde la anglofobia. La teoría de Buckle pretendía "subordinar todos los genios al genio británico, y el curso del desarrollo de todas las civilizaciones al de la civilización inglesa" ${ }^{38}$ Para contrarrestar la leyenda negra, Martins articuló una teoría del genio peninsular destacando la belicosidad, la espiritualidad y el abandono de los asuntos comerciales en clave positiva. Como contrapeso a la preponderancia política septentrional, realizó una profunda caracterización del espíritu peninsular, subrayando elementos como la independencia o el heroísmo. Esta civilización había tenido la misión histórica de explorar el mundo y si se reagrupara ocuparía "la cuarta parte de la superficie terrestre del globo". 39

\footnotetext{
${ }^{37}$ Ideas que continuaría en 1897 Edmond Demolins en A quoi tient la supériorité des anglo-saxons?, traducida al español en 1899 por Santiago de Alba, muy criticada en ambos lados del Atlántico. Arreguine, En qué consiste la superioridad de los latinos; Altamira, "Latinos y anglosajones".

${ }^{38}$ Martins, Historia de la civilización ibérica, p. 25. Véase estudio introductorio de Matos.

${ }^{39}$ Martins, Historia de la civilización Ibérica, p. xxviii.
} 
En el último tercio del siglo XIX destacó la voz americanista de Rafael María Labra, presidente de la Sociedad Abolicionista entre 1872 y 1888. En línea con el pensamiento historiográfico liberal, justificaba las independencias americanas con un binomio discursivo opresión-reacción. ${ }^{40}$ Sin embargo, Labra defendía la continuidad identitaria y cultural entre los pueblos peninsulares y americanos desde una perspectiva regeneracionista-krausista. La clave estaba en la renovación educativa, que lo llevó a dirigir el Congreso Pedagógico Hispano-Portugués-Americano en 1892, en el contexto de las conmemoraciones del descubrimiento. El de Labra era un discurso patriótico de redención nacional a partir del acercamiento confraternal americano.Altamira continuó su conceptualización americanista desde un punto de vista cientifista y trató de combatir desde el método historiográfico la leyenda negra, sin caer en la vindicación del pasado colonial español. A partir del pensamiento nacionalista de Fichte, articuló una genealogía de la civilización española con el fin de "restaurar el crédito de la historia, para devolver al pueblo español la fe en sus cualidades, en su aptitud para la vida civilizada". ${ }^{41}$ El viraje hacia América también respondía a la búsqueda de patrones políticos más progresistas y a la necesidad de establecer lazos literarios con los países iberoamericanos que pudieran hacer frente culturalmente al poderío literario francés o inglés.

Las ideas de confraternización espiritual de Altamira fueron tachadas de neocoloniales por algunos autores americanos ya entrado el siglo xx, como el antropólogo cubano Fernando Ortiz. En 1911, en La reconquista de América, criticaba que tras la máscara de cordialidad del hispanismo cultural planteado por Labra o por Altamira se escondía un interés hegemónico de España por sus antiguas colonias. No se trataría de una comunión cosmopolita, sino de un anhelo neocolonial panhispano

40 LABra, La pérdida de las Américas.

41 Altamira, Psicología del pueblo español, p. 161. 
- “imperialismo manso" - comparable con el pangermanismo o el paneslavismo. Ante la decadencia peninsular, España buscaba un vehículo de regeneración en el recuerdo de su pasado imperial. Para celebrar y legitimar su propia existencia, la intelectualidad española había vuelto la vista al descubrimiento de América. Así mismo, según Ortiz, la focalización en el fenómeno civilizatorio pretendía contrarrestar la leyenda negra que relacionaba la acción española con la barbarie..$^{42}$ Sin embargo, Altamira insistía en que su propuesta era americanista. Para evitar el imperialismo era necesario construir lazos asociativos y culturales -"el regreso a lo más hondo y troncal de nuestro espíritu". ${ }^{43}$ Pero la postura de Ortiz no fue unánime al otro lado del Atlántico, siendo la respuesta mayoritaria en horizontes políticos, económicos e intelectuales favorables a las proyecciones de Altamira, como atestigua, por ejemplo, el decreto de 1917 del presidente de Argentina, Hipólito Irigoyen, declarando el 12 de octubre fiesta nacional.

\section{REGENERACIÓN EXPANSIVA}

El pensamiento político del siglo xix se vio fuertemente influenciado por el cosmopolitismo ilustrado y por el ideal de progreso, por la consideración evolutiva del tiempo que situaba los acontecimientos en un camino histórico unívoco dirigido hacia un fin perfectible. La confianza en el progreso -conceptualizada por Saint-Simon o por Comte, entre otros-articulaba la prosperidad de los tiempos modernos en una sucesión de etapas de crecimiento que culminarían en la perfectibilidad de la humanidad.

${ }^{42}$ UCelay-Da Cal, “¿Cómo convertir a los perdedores en ganadores?”, señala cómo las proyecciones imperialistas o espirituales hacia América fueron mecanismos de regeneración de países que se habían quedado relegados de la modernidad.

${ }^{43}$ Altamira, La política de España en América, p. 75. 
Así mismo, el ferrocarril, el vapor, el telégrafo favorecían la aceleración de los procesos de homogeneización a escala global.

La teoría del equilibrio contractual entre las naciones se consolidó a lo largo del setecientos, sobre todo a raíz de la publicación de Hacia la paz perpetua, de Immanuel Kant, en 1795. Esta comunión universal de la condición humana debía ser salvaguardada por todas las naciones, evitando los abusos de las potencias sobre las naciones débiles. La humanidad era la condición sine qua non de los nacidos en el seno de la especie, si bien presentaba diferentes grados de evolución entre las civilizaciones. ${ }^{44}$

Los proyectos cosmopolitas ilustrados continuaron en el siglo xix como anhelos de consecución de la paz entre las naciones y de la apertura de fronteras que favoreciesen el libre desarrollo de los intercambios económicos y culturales. Con tales fines en 1849 se convocó al I Congreso de la Paz en París, presidido por Víctor Hugo, donde se profetizó la paulatina unión política y moral de los estados europeos en torno a valores democráticos, y la Liga Internacional de la Paz y la Libertad en 1867. Una de las claves para alcanzar la paz perpetua, según el periodista liberal Latino Coelho, pasaba por la disminución de los estados, haciendo clara referencia a la integración de Portugal en una hipotética unión ibérica. "Cada nación pequeña que se levante de nuevo en la tierra es una presa que despierta la ambición de las grandes potencias; [...] lanza una nueva simiente de guerra" ${ }^{45}$ Estas manifestaciones de universalismo compartieron expectativas políticas con los procesos de construcción de los estados-nación. La fe en el progreso y en la fraternidad universal tenía que convivir, según Latino Coelho, con el principio de nacionalidad -“a nacionalidade é o egoísmo dos povos. O Cosmopolitismo, tendencia visível dos estados cultos". ${ }^{46}$

\footnotetext{
${ }_{44}$ Todorov, El espiritu de la Ilustración; Febvre, Europa.

45 Coelho, "Prólogo português", p. 27.

46 Coelho, "Prólogo português", p. viii.
} 
Al calor de los acontecimientos revolucionarios de 1848, de los procesos abiertos de unificación en Alemania e Italia y de la simbiosis de los anhelos progresistas y universalistas, surgieron en la Península proyectos iberistas con múltiples aristas, que podemos sintetizar en tres corrientes mayoritarias. Por un lado, los partidarios de la unión dinástica de España y Portugal bajo una única monarquía que permitiese la regeneración nacional en el espacio internacional y evitara las injerencias de los gobiernos franceses e ingleses. En este subgrupo podemos destacar las propuestas de Sinibaldo de Más, Latino Coelho y Juan Valera, partidarios de un paulatino acercamiento que limase las narrativas historicistas antiibéricas. De esta manera se ampliaría el territorio, las capacidades comerciales, la riqueza, la demografía y las fuerzas militares. Este iberismo era principalmente unitario en cuanto a su fórmula institucional monárquica. En segundo lugar, la opción republicana, bien unionista, bien federalista, heredera de los anhelos internacionalistas que abogaban por la confraternización de los pueblos a partir de acuerdos democráticos entre iguales. Sus ideólogos compartieron la crítica al modelo centralista e imperialista de unión o anexión y proyectaron una sociedad civil basada en las libertades políticas, conformada por pactos sinalagmáticos entre municipios y federaciones, tal y como había señalado Proudhon, cuya obra llegó a la Península a partir de las traducciones de Pi y Margall y Antero de Quental. Para evitar la preponderancia española, dividían el territorio peninsular en múltiples federaciones de tamaño semejante. Hablamos de autores como Sixto Cámara, Fernando Garrido, Henriques Nogueira, Castelar, José María Orense, Pi y Margall o Antero de Quental. Por último, una noción imperialista de culminación del territorio peninsular a partir de la conquista, como la planteada por Pío Gullón. Esta última generó una gran polémica en la opinión pública portuguesa y propició la creación de la "Comissão $1^{\circ}$ de Dezembro", una asociación civil cuyo fin era mantener vivo en la sociedad portuguesa el recuerdo de los 
años de dominación de los Felipes - y por tanto, de Castilla o España- y contrarrestar las teleologías iberistas. En cualquiera de los casos, subyacía la noción de decadencia de los pueblos peninsulares y su necesaria regeneración y revitalización tanto moral como económica y social. ${ }^{47}$ Así mismo, los iberismos, independientemente de sus culturas políticas de referencia, partían de una noción de espacio y tiempo compartidos que legitimaba en el orden natural de las naciones la unidad y explicaba la fragmentación peninsular por el interés de las dinastías, no así de sus pueblos.

El cambio de hegemonías hacia el norte de Europa, constatado tras el triunfo de Prusia sobre Francia en 1871 - así como en las derrotas de Italia en Adua en 1896 y de Francia en Fachoda en $1898-$, provocó la solidaridad internacional federalista en torno a la historia del Mediterráneo y la raza latina. La vindicación del espacio, la historia y el espíritu de la Europa meridional pretendía hacer frente al incipiente poder prusiano, británico y estadounidense., que había alterado el equilibrio de poderes en Europa y América. Los estados del sur debían unir sus esfuerzos en torno a un proyecto político, económico y civilizacional compartido que se presentara como alternativa a la hegemonía septentrional. El panlatinismo había sido planteado en 1862 por Prosper Vallerange como mecanismo de superación de la decadencia de los pueblos de sur, que además compartían vínculos lingüísticos, culturales e históricos. ${ }^{48}$ Ese mismo año, Charles de La Varenne formuló la propuesta de una raza latina en oposición al pangermanismo y paneslavismo. ${ }^{49} \mathrm{La}$ unidad de la raza latina - italianos, franceses, españoles y portugueses - se justificaba por una unidad caracterológica, de raza e historia, así como por el proyecto de futuro regeneracionista. A la unificación italiana

\footnotetext{
47 Remitimos a Rina Simón, Iberismos; Matos, "Was Iberism a Nationalism?”; Catroga, "Nacionalismo e ecumenismo".

48 Vallerange, Le Panlatinisme.

49 La VAREnne, La Fédération latine.
} 
le seguiría la ibérica, clave para superar las interferencias británicas y, finalmente, la de los pueblos del Mediterráneo. En la formulación del panlatinismo en la Península destacó Emilio Castelar -"la raza latina puede ejercer en el Nuevo Mundo un apostolado superior a la raza anglosajona",$-{ }^{50}$ Fernando Garrido en el contexto de la Revolución Gloriosa y, especialmente, el republicano-federalista Magalhães Lima. ${ }^{51}$ La raza latina era más que un anhelo espiritual o literario: "ha personificado también esa intuición mágica del genio que vislumbra y adivina lo que la labor mecánica y perseverante de otras razas no podría jamás alcanzar [...] al lado de Homero, Dante, Cervantes y Víctor Hugo [...]" ${ }^{52}$ En definitiva, la raza latina era una civilización de destino, había regalado a la historia universal la unidad espiritual del catolicismo, la unidad civil del derecho romano, la revolución francesa, el arte del Renacimiento y el descubrimiento del Nuevo Mundo.

Los regeneracionismos iberistas y el progresismo internacionalista, así como las narrativas nacionalistas conservadoras, articularon un incipiente pensamiento americanista, resultado de la búsqueda de afinidades culturales, raciales, históricas o lingüísticas y del deseo de superar la decadencia proyectándose hacia nuevos territorios, recuperando una unidad ideal fragmentada por las disonancias entre el liberalismo americano y el absolutismo peninsular. En un primer término, a mediados del siglo XIx, la proyección americana se concretó en llamamientos progresistas a la confraternización, al libre comercio y a la búsqueda de alianzas atlánticas ante la paulatina basculación del poder europeo hacia el norte. Como en el caso del panlatinismo,

\footnotetext{
${ }^{50}$ Castelar, "La unión de España y América".

${ }^{51}$ En 1874 tradujo al portugués la obra de Lemonnier. En 1890, tras la "crisis del Ultimátum”, Lima recorrió Europa promoviendo el proyecto de federación latina en defensa de los pueblos meridionales. Véase Lima, Episódios da minha vida.

${ }^{52}$ Enrique Vera, "La Alianza Latina”, La República (30 abr. 1890).
} 
el hispanoamericanismo se nutrió de la búsqueda de elementos redentores de la identidad nacional en la constitución de alianzas o comunidades transnacionales. Destacamos en esta línea a los republicanos Castelar y Fernando Garrido, los escritores Leopoldo Alas Clarín ${ }^{53}$ y Oliveira Martins, el catalanista Cases Carbó o el nacionalcatólico Menéndez Pelayo.

\section{AMERICANISMO ANTES DE LOS DESASTRES}

Las expectativas hispanoamericanistas, si bien se remontan cronológicamente a las mismas independencias, comenzaron a ocupar espacios importantes en la opinión pública peninsular a raíz del fracaso de la Revolución Gloriosa y de los iberismos. La resignificación de la patria en términos conservadores y el arrinconamiento de los programas peninsulares al margen de las utopías revolucionarias abrieron el horizonte a las proyecciones americanistas. ${ }^{54}$ De esta forma, el americanismo se convirtió en un mecanismo de redención de la nación y de la raza latina o hispana ante la hegemonía cultural, política y económica de los pueblos septentrionales. El movimiento fue, de manera general, en ambas direcciones, señalando diferentes voces americanas la necesidad de reivindicar la civilización hispana frente al expansionismo norteamericano. En 1868, el colombiano José María Torres Caicedo establecía una contraposición entre los pueblos latinos, volcados a los valores

${ }^{53}$ Leopoldo Alas Clarín, "Palique”, Madrid Cósmico (4 oct. 1890): "Mi opinión particular es que España, Portugal y la América española y portuguesa deben formar, antes o después, una sola nación internacionalista".

${ }^{54}$ Véase Rodríguez-Esteban, “Geopolitical perspectives in Spain”. Las restauraciones políticas conservadoras tipificaron los iberismos como agentes desestabilizadores y no regeneradores, lo que alcanzó al republicanismo luso, que evolucionó del iberismo federalista al unionismo con un claro discurso nacionalista. Rina Simón, Iberismos; Matos, "Iberismo e hispanismo". 
religiosos, y los anglosajones, focalizados en el comercio y desprovistos de condiciones espirituales. ${ }^{55}$

El elenco de publicaciones con una dimensión americanista es lo suficientemente contundente como para poder afirmar el amplio espacio ideológico que ocuparon estas proyecciones en el pensamiento político español. Entre 1853 y 1855 se publicó la Revista Española de Ambos Mundos; entre 1857 y 1874, y 1879 y 1886, La América; entre 1864 y 1867, la Revista Hispano-Americana; entre 1870 y 1921, La Ilustración Española e Hispanoamericana; entre 1877 y 1879, La Academia: revista de cultura hispano-portuguesa, latino-americana; y entre 1881 y 1891, la Revista Hispanoamericana. Estas publicaciones, además de ofrecer informaciones generales sobre ambos lados del Atlántico, fueron plataforma de proyección de los discursos hispanoamericanistas. El 25 de enero de 1885, se constituyó la asociación periodística Unión Iberoamericana, en la que participaron amplios sectores del abanico político. Estuvo presidida por el senador conservador Mariano Cancio Villamil y contó con el patrocinio financiero del marqués de Comillas y el apoyo del ministro de estado Segismundo Moret, los tres con intereses económicos en las colonias de Cuba, Puerto Rico y Filipinas. El artículo primero de sus estatutos señalaba el objetivo de "estrechar las relaciones sociales, económicas, científicas, literarias y artísticas de España, Portugal y las naciones americanas, donde se habla el español y el portugués [...]”. El proyecto de la Unión Iberoamericana se concretó en doce puntos programáticos: reconocimiento de títulos académicos, supresión de aduanas terrestres entre España y Portugal, firma de tratados

${ }_{55}$ Torres Caicedo, Estudios sobre el gobierno inglés. Para el hispanoamericanismo en México remitimos a Granados García, Los debates sobre España. En la construcción de las nuevas republicas americanas destacaron las narrativas dicotómicas que enfrentaban el pasado colonial español de dominación con la liberación nacional. Véase Pérez Vejo, España en el debate y "La hispanofobia como elemento de movilización”. 
de cooperación con las repúblicas americanas, convenios postales, proyecto de un edificio para una exposición permanente iberoamericana, habilitación de locales en América de la asociación, acuerdos de propiedad literaria, reorganización colonial de Cuba y Puerto Rico, formación de personal especializado en administración ultramarina, "españolizar” Cuba y Puerto Rico, aumentar el presupuesto de los servicios civiles y análisis del atraso y de la propuesta de medidas de regeneración a nivel municipal. ${ }^{56}$

En el caso luso, los descubrimientos marítimos, el pionerismo y la proyección atlántica fueron elementos centrales en las narrativas nacionalistas. Portugal vivió su particular ciclo conmemorativo imperialista con las celebraciones en 1880 de Camões y en 1894 de Enrique el Navegante. El primero de los acontecimientos, diez años antes del ultimátum inglés, estuvo protagonizado por una intensa campaña de nacionalización del republicanismo, que utilizó las conmemoraciones para presentarse como partido regenerador, alternativa a la decadencia de los Braganza. Las conmemoraciones de Camões fueron modélicas en la ritualización historicista a partir de los principios comtianos y positivistas: una liturgia cívica y un nuevo catecismo de los pueblos basado en héroes que habían destacado por sus hazañas artísticas o científicas. Las celebraciones combinaron significados patrióticos con otros cívicos y moralizantes. Republicanos y positivistas como Teófilo Braga, Ramalho Ortigão, Luciano Cordeiro y Magalhães Lima lideraron los actos. En 1880 se conmemoraba la muerte del poeta que había cantado las hazañas ultramarinas de Portugal, pero también se celebraba el fin de la edad de oro portuguesa y el recuerdo de la conquista española en 1580. El hecho de que los actos estuvieran protagonizados por republicanos desvió la atención desde la reminiscencia colonial

56 "Unión Ibero-Americana: estatus y reglamentos", pp. 5-8. Más asociaciones en Sepúlveda, "Medio siglo de asociacionismo”. 
hasta la celebración de las artes, el progreso o las ciencias. ${ }^{57}$ Según Oliveira Martins, las naciones pequeñas, en el horizonte convulso de los imperialismos, debían mostrar su espíritu patriótico - en línea con Renan-, manifestar y convencerse cada día de su existencia. ${ }^{58} \mathrm{La}$ respuesta patriótica conservadora y monárquica llegó con las conmemoraciones del infante don Enrique en 1894, ocurrido ya el ultimátum, centrándose los actos en la épica y el pionerismo portugués. ${ }^{59}$

Las conmemoraciones de 1892 del descubrimiento de América - "la celebración del centenario del Renacimiento Peninsular",$-{ }^{60}$ desarrolladas con especial simbolismo en Madrid y en La Rábida constataron la potencialidad del recuerdo americano y su adaptabilidad semántica a diferentes culturas políticas. Para la Unión Ibero-Americana, el descubrimiento había sido el hecho más importante de su época. La asociación aprovechó la efeméride para publicar un nuevo programa de acción: constitución de un instituto iberoamericano, restauración del sepulcro de Colón en La Habana, declaración del 12 de octubre como "fiesta cívica" bajo el nombre de Fiesta de la Raza, y declaración como monumento nacional de la casa de Colón en Valladolid. ${ }^{61}$ En el 12 de octubre confluyeron múltiples intereses que encontraron un espacio ideológico cómodo en el recuerdo de la labor evangelizadora de España, del heroísmo de los conquistadores, o en la confraternización de pueblos que compartían historia, cultura y lengua. En las celebraciones, por tanto, confluyeron imaginarios locales, regionales, nacionales y cosmopolitas. ${ }^{62}$ El número de obras publicadas, especiales en

\footnotetext{
${ }^{57}$ Republicanismo, positivismo y patriotismo de las celebraciones en BRAGA, Camões; Jỗo, "Dia de Camões".

${ }^{58}$ Martins, Camões, p. 236.

${ }^{59}$ Véase Torgal, Mendes y Catroga, História da História, pp. 226 y ss.

${ }^{60}$ Ortigão, Pela terra alheia, p. 173.

${ }^{61}$ Sepúlveda, El sueño de la Madre Patria, pp. 77 y ss.

${ }^{62}$ Dicho arraigo culminaría en 1918, cuando el 12 de octubre fue declarado
} 
prensa y folletines fue abrumador. Juan Valera reeditó sus Cartas americanas, publicadas originalmente en 1889. También fue el encargado de coordinar la obra El Centenario, una historia polifónica del descubrimiento en la que además defendía el pragmatismo de la celebración: regenerar España a través del contacto comercial y cultural con América. ${ }^{63}$ Por su parte, Cánovas del Castillo escribió en numerosas publicaciones sobre la cuestión e impartió en el Ateneo de Madrid, en febrero de 1891, una conferencia sobre la historiografía de la conquista, muy crítico con los autores extranjeros y nacionales que habían aceptado la leyenda negra ${ }^{64}$ Incluso se escribieron odas a la esposa de Colón. En el horizonte del pensamiento nacionalcatólico, Menéndez Pelayo aprovechó para dotar a la conmemoración de un sentido religioso a través de la memoria de la evangelización. A rebufo de la celebración, publicó una antología de la poesía hispanoamericana entre 1893 y 1895 . No pudieron faltar los hispanoamericanistas que llevaban reivindicando este horizonte de expectativas desde la década de 1850: Castelar ${ }^{65}$ y Labra, y la élite cultural y política del momento: Emilia Pardo Bazán, Luis Vidart y Francisco Pi y Margall. ${ }^{66}$ En 1892, el protagonista de

fiesta nacional con el nombre de Día de la Raza. Véase el proceso de institucionalización de la fiesta en Serrano, El nacimiento de Carmen, pp. 313 y ss. Un repaso por los diferentes nombres que adquirió la conmemoración, en Marcilhacy, "Las figuras de la 'Raza'”.

${ }_{63}$ Palabras de Valera en El Centenario: "Nuestras miras en la celebración del centenario deben dirigirse a que esta gran fiesta lo sea de suprema concordia, donde nos honremos y amemos, poniendo, por encima de la discrepancia política de los diversos estados, un sentimiento de familia y una común aspiración que en esfera más amplia nos identifiquen. Todo lo cual puede y debe tener fin práctico inmediato, ya por el desarrollo de nuestro comercio material [...]; ya por el trato y convivencia mental, que vengan a hacerse más frecuentes entre España y América [...]”.

${ }^{64}$ Cánovas del Castillo, Criterio histórico.

${ }^{65}$ Peralta Ruiz, "Emilio Castelar y el hispanoamericanismo".

${ }^{66}$ Este último, autor de América en la época del descubrimiento y de Historia de la América antecolombina, en 1892, recalcaba el legado cultural y el avance 
la conmemoración fue Cristóbal Colón, una figura fácilmente asimilable desde perspectivas ideológicas muy variadas, para convertirse en las décadas posteriores en la fiesta de la evangelización y la conquista de América. ${ }^{67}$

A partir de la función historicista de estas liturgias del recuerdo se intentaba estimular una serie de efectos pedagógico patrióticos: creación de un clima de movilización nacional, respuesta al decadentismo y aliento del Renacimiento. Es por ello que la figura celebrada, Camões o Colón, sólo podía ser descrita desde el panegírico, lo que nos muestra cómo el fenómeno conmemoracionista se fundamentó en un trabajo acrítico de historización, silenciando las disonancias críticas interpretativas. Estas fiestas jugaron un importante papel en la nacionalización de la sociedad y en la toma de conciencia de la decadencia y la necesaria regeneración-renacionalización. Pero en dichas conmemoraciones también se estaba representando un determinado modelo de nación o estado, excluyente de otras culturas políticas que no participaran de los significados y significantes de la celebración. ${ }^{68}$

En relación con la lengua, la Real Academia Española inició un acercamiento hispanoamericano en 1861, en pleno debate sobre si el uso del español en América o la presión cultural norteamericana en el continente tergiversaban la lengua. El monopolio lingüístico se quebró y, cinco años después, la Academia ya contaba con seis académicos correspondientes americanos. En 1873 comenzaron a establecerse sedes en América. ${ }^{69}$

civilizacional de los pueblos americanos antes de la conquista. Su obra historiográfica suponía la aceptación de las narrativas de la "leyenda negra”.

67 Sagasta, Gazeta de Madrid (29 feb. 1888): “Desde que cundió la afición y se estableció la costumbre de dar cierto culto a los héroes celebrando magníficas fiestas seculares, acudió a la mente de muchos españoles la idea de consagrar una de estas fiestas al hombre extraordinario cuya gloria refleja mayor luz sobre España”.

68 JoÃo, Memória e Império; Catroga, Entre Deuses e Césares.

69 Sepúlveda, El sueño de la Madre Patria, p. 69. 
La historiografía de los desastres coloniales de 1890 y 1898 ha eclipsado una crisis del pensamiento europeo, si cabe, más relevante para las culturas políticas peninsulares. Nos referimos a la crisis del positivismo, cuyos ideales de conformación de una humanidad perfecta por la vía del progreso comenzaron a ser cuestionados desde diferentes sectores. La maquinaria de la sociedad no era tan previsible como habían vaticinado Comte y sus seguidores. El pensamiento progresista español, que había protagonizado la Revolución Gloriosa, fue apartado de la restauración canovista, y con él el krausismo y el europeísmo cientifista de la Institución Libre de Enseñanza. Ante esta crisis generacional, irrumpieron figuras como Labra y Altamira, con el propósito de rescatar un pensamiento excluido de la toma de decisiones políticas. De forma parcial, las expectativas hispanoamericanistas fueron fagocitadas por el pensamiento conservador e imperialista que desde el pionerismo en Portugal o desde los mitos del descubrimiento en España identificaron los caracteres nacionales en la conquista y evangelización del continente, transformando las proclamas de confraternización cultural progresivamente en discursos sobre la hegemonía de la civilización hispana en América, proceso que culminaría en las narrativas franquistas. ${ }^{70}$ Por su parte, el concepto de decadencia se extendió como fórmula de identificación de la crisis del positivismo y de la idea de progreso. En 1893, Salmerón tradujo al español Degeneración, de Max Nordau, una obra clave que alcanzó gran repercusión entre las élites intelectuales europeas. Para Nordau, la sociedad moderna se encaminaba hacia la decadencia, de ahí el surgimiento de literaturas regeneracionistas en todo el continente que intentaron invertir la trayectoria descendente. ${ }^{71}$

\footnotetext{
70 Calle Velasco, "Hispanoamericanismo"; también González Calleja, "Hispanidad".

${ }_{71}$ Para el caso español remitimos a Serrano, Final del Imperio; Balfour, El fin del Imperio español.
} 


\section{CONCLUSIONES}

A lo largo de estas páginas hemos intentado constatar el fuerte proceso de nacionalización española y portuguesa a partir de las proyecciones americanas, remontando el proceso a los orígenes del estado-nación liberal, y no a las crisis coloniales finiseculares. Ante la toma de conciencia de la decadencia peninsular, la reconquista colonial o espiritual de América se convirtió en uno de los referentes centrífugos de la regeneración peninsular y en escenario de combate entre diferentes narrativas historiográficas que se posicionaron ante el fenómeno de múltiples maneras.

El hispanoamericanismo que surgió a mediados del siglo XIX del pensamiento progresista y liberal fue parcialmente apropiado a finales de siglo por posturas más esencialistas y conservadoras que relacionaron el descubrimiento y conquista de América con una labor providencial marcadora de la identidad española, de su evangelización y del dominio imperial y espiritual sobre otros territorios. La resignificación conservadora de estas expectativas ha condicionado profundamente la interpretación del hispanoamericanismo, incidiendo en su carácter neoimperialista y como respuesta nacionalista al desastre de 1898. Sin embargo, un recorrido por el concepto en el siglo xIX nos permite cuestionar esta interpretación, abriendo sus significados a la conformación poliédrica de las culturas políticas y de los nacionalismos, así como al pensamiento federal y progresista.

Es por esto que debemos entender el hispanoamericanismo del ochocientos como una búsqueda de solidaridad cultural o civilizacional de los pueblos ibéricos o latinos ante el cambio de hegemonía internacional y la creciente influencia del horizonte germánico y anglosajón en la Península y en América. Este hispanoamericanismo se consolidó en los imaginarios nacionalistas, pero no así en acciones concretas que incluyeran la participación del otro. 


\section{REFERENCIAS}

Almeida Garrett, Yoão Baptista da Silva Leitáo de, Portugal na balança da Europa, Porto, Imp. V. Moré, 1867 [1830].

Altamira, Rafael, "Latinos y anglosajones”, en Cuestiones Hispanoamericanas, Madrid, E. Rodríguez Serra, 1900, pp. 57-67.

Altamira, Rafael, Psicología del pueblo español, Madrid, Biblioteca Nueva, 1977 [1902].

Altamira, Rafael, La politica de España en América, Valencia, EdeTA, 1921.

Álvarez Junco, José, Mater Dolorosa. La idea de España en el siglo XIX, Madrid, Taurus, 2001.

Andreu Miralles, Xavier, El descubrimiento de España. Mito romántico e identidad nacional, Madrid, Taurus, 2016.

Archilés i Cardona, Ferran, Marta García Carrión e Ismael Saz Campos (eds.), Nación y nacionalización. Una perspectiva europea comparada, Valencia, Universitat de València, 2013.

Arreguine, Víctor, En qué consiste la superioridad de los latinos sobre los anglosajones, Buenos Aires, Publicación de la Enseñanza Argentina, 1900.

BALFour, Sebastian, El fin del Imperio español, 1898-1923, Barcelona, Crítica, 1997.

Bernabeu Albert, Salvador, 1892: El IV centenario del descubrimiento de América en España, Madrid, Consejo Superior de Investigación Científica, 1987.

Blanco, Alda, "Imperial Nostalgia or Modern Colonialism?", en A Contra corriente, 5 (2007), pp. 1-11.

Blanco, Alda, Cultura y conciencia imperial en la España del siglo XIX, Valencia, Publicaciones de la Universidad de Valencia, 2012.

Bourdieu, Pierre, “Le Nord et le Midi: Contribution à une analyse de l'effet Montesquieu”, en Actes de la recherche en Sciences Sociales, 35 (1980), pp. 21-25. 
Braga, Teófilo, Camões e o Sentimento Nacional, Porto, E. Chardon, 1891.

Calafate, Pedro, José Luis Mora García, Xavier Asenjo Bullón (coords.), Filosofía y literatura en la peninsula ibérica. Respuestas a la crisis finisecular, Madrid, Fundación I. Larramendi, Centro de Filosofía da Universidade de Lisboa, Asociación de Hispanismo Filosófico, 2012.

Calle Velasco, María Dolores de la, "Hispanoamericanismo. De la fraternidad cultura a la defensa de la hispanidad", en De Vega, De Luis Martín y Morales Moya (eds.), 2004, pp. 151-172.

Cánovas del Castillo, Antonio, Historia de la decadencia de España desde el adveniminto de Felipe III al trono hasta la muerte de Carlos II, Madrid, Biblioteca Universal, 1854.

Cánovas del Castillo, Antonio, Discurso sobre la nación, Madrid, Biblioteca Nueva, 1997 [1882].

Cánovas del Castillo, Antonio, Criterio histórico con que las distintas personas que en el descubrimiento de América intervinieron han sido después juzgadas, Madrid, Est. Tip. Sucesores de Rivadeneyra, 1892.

Castelar, Emilio, "La unión de España y América”, en Colección de los principales artículos políticos y literarios, Madrid, Imp. de Gómez Marín, 1859, pp. 28-36.

CASTro, Adolfo de, Examen filosófico sobre las principales causas de la decadencia española, Cádiz, Imp. de D. Francisco Pantoja, 1852.

Catroga, Fernando, "Nacionalismo e ecumenismo. A questão ibérica na segunda metade do século xIX", en Cultura Histórica e Filosofia, 4 (1984), pp. 419-463.

Catroga, Fernando, Entre Deuses e Césares. Secularização, laicidade e religião civil, Coimbra, Almedina, 2006.

Coelho, José Maria Latino, "Prólogo português", en Sinibaldo de Mas y SANZ, La Iberia. Memoria sobre la conveniencia de la unión pacífica y legal de Portugal y España, Madrid, Imp. de Rivadeneyra, 1854 [1851].

De Carvalho, José Murilo, Miriam Halpern Pereira, Gladys Sabina RibeiRO, Maria João VAz (orgs.), Linguagems e fronteiras do poder, Lisboa, Instituto Universitário de Lisboa, 2012. 
De Vega, Mariano Esteban, Francisco De Luis Martín y Antonio Morales Moya (eds.), en Jirones de hispanidad. España, Cuba, Puerto Rico y Filipinas en la perspectiva de dos cambios de siglo, Salamanca, Universidad de Salamanca, 2004.

EAstMan, Scott, "America has escaped from our hands: Rethinking empire, identity and independence during the trienio liberal in Spain, 1820-1823", en European History Quarterly, 41 (2011), pp. 248-443.

Febvre, Lucien, Europa. Génesis de una civilización, Barcelona, Crítica, 2001 [1944-1945].

Fernández Sebastián, Javier y Juan Francisco Fuentes (dirs.), Diccionario político y social del siglo XIX español, Madrid, Alianza, 2002.

Feros, Antonio, "Spain and America: All is one. Historiography of the Conquest and Colonization of the Americas and National Mythology in Spain, c. 1892-c. 1992", en Schmidt-Nowara y Nieto-Phillips (eds.), 2005, pp. 109-134.

Ferrer del Río, Antonio, Decadencia de España. Historia del levantamiento de las Comunidades de Castilla, Madrid, Tip. Mellado, 1850.

Forcadell, Carlos, Ignacio Peiró y Mercedes Yusta, El pasado en construcción. Revisionismos en la historiografía contemporánea, Zaragoza, Institución Fernando el Católico, 2015.

Fuentes, Juan Francisco, “Regeneración”, en Fernández Sebastián y FuenTES (dirs.), 2002, pp. 603-608.

García CÁrcel, Ricardo, La herencia del pasado. Las memorias históricas de España, Madrid, Galaxia Gutenberg, 2012.

GARCÍA CÁRCel, Ricardo (coord.), La construcción de las Historias de España, Madrid, Fundación Carolina, Marcial Pons, 2004.

GARRIDO, Fernando, La regeneración de España, Barcelona, Salvador Manero, 1860.

González Calleja, Eduardo, “Hispanidad”, en Fernández Sebastián y Fuentes, 2002, pp. 617-623. 
Goode, Joshua, Impurity of Blood. Defining Race in Spain, 1870-1930, Baton Rouge, LSU Press, 2009.

GutiérRez Solana, Valentín, La gran familia hispanoamericana, Madrid, Imp. Hispánica, 1926.

Granados García, Aimer, Los debates sobre España: el hispanoamericanismo en México a finales del siglo XIX, México, El Colegio de México, 2005.

Guardia, Carmen de la y Juan Pan-Montojo, "Reflexiones sobre una historia transnacional”, en Studia Historica. Historia Contemporánea, 16 (1998), pp. 9-31.

JoÃo, Maria Isabel, Memória e império: comemorações em Portugal (18891960), Lisboa, Fundação Calouste Gulbenkian, 2002.

João, Maria Isabel, "Dia de Camões e de Portugal: breve história de uma celebração nacional (1880-1977)", en Revista de Historia Jerónimo Zurita, 86 (2011), pp. 19-34.

Koselleck, Reinhart, historia/Historia, Madrid, Trotta, 2004.

LA VARENNE, Charles de, La Fédération latine per les unités française, italienne et ibérique, París, E. Dentu, 1862.

Labra, Rafael María de, La pérdida de las Américas, Madrid, Imp. de Francisco Roig, 1869.

LimA, Magalhães, Episódios da minha vida, Lisboa, Liv. Universal, 1927, vol. II.

LitvaK, Lily, España 1900. Modernismo, anarquismo y fin de siglo, Barcelona, Anthropos, 1990.

López-Vela, Roberto, “De Numancia a Zaragoza. La construcción del pasado nacional en las historias de España del ochocientos”, en García CÁrcel (coord.), 2004, pp. 195-298.

Lowenthal, David, El pasado es un país extraño, Madrid, Akal, 1998.

Marcilhacy, David, Raza hispana. Hispanoamericanismo e imaginario nacional en la España de la Restauración, Madrid, Centro de Estudios Políticos y Constitucionales, 2010. 
Marcilhacy, David, "América como vector de regeneración y cohesión para una España plural: La Raza y el 12 de octubre”, en Hispania, 244 (2013), pp. 501-524.

Marcilhacy, David, "Las figuras de la 'Raza': de la España mayor a la comunidad iberoamericana, perspectivas (post)imperiales en el imaginario español”, en Historia y Política, 35 (2016), pp. 145-174.

Martins, Joaquim Pedro de Oliveira, Camões, Lisboa, Guimarães Ed., 1986 [1872].

Martins, Joaquim Pedro de Oliveira, Historia de la civilización ibérica, Pamplona, Urgoiti, 2009 [1879].

Mas y SAnz, Sinibaldo de, La Iberia. Memoria sobre la conveniencia de la unión pacífica y legal de Portugal y España, Madrid, Imp. De Rivadeneyra, 1854.

Matos, Sérgio Campos, Consciência histórica e nacionalismo, Lisboa, Livros Horizonte, 2008.

Matos, Sérgio Campos, "Was Iberism a Nationalism? Conceptions of Iberism in Portugal in the Nineteenth and Twentieth Centuries", en Portugal Studies, 25 (2009), pp. 169-193.

Matos, Sérgio Campos, "Linguagem do patriotismo em Portugal: da crise do Antigo Regime à I Republica”, en De Carvalho, Pereira, Ribeiro, Vaz (orgs.), 2012, pp. 35-54.

Matos, Sérgio Campos, "Iberismo e hispanismo: Portugal e Espanha (18901931)”, en Calafate, Mora García, Asenjo Bullón (coords.), 2012, pp. 251-271.

Matos, Sérgio Campos, "Patria, nación, nacionalización: el caso portugués en el siglo xix”, en Archilés i Cardona, García Carrión, y Saz Campos (eds.), 2013, pp. 25-47.

Matos, Sérgio Campos, “CCómo convivir con la pérdida? Historiografía, conciencia histórica y política en Portugal dentro del contexto peninsular", en Forcadell, Peiró y Yusta, 2015, pp. 249-274.

Mendíbil, Pablo de, Cuadro histórico que en forma de cartas escribió el Lic. D. Carlos María Bustamante, Londres, Ackermann, 1828. 
Miller, Alexei y Stefan Berger (eds.), Nationalizing Empires, Nueva York, Central European University Press, 2015.

Morales Moya, A. (coord.), Los 98 ibéricos y el mar, Madrid, Sociedad Estatal de Lisboa 98, 1998.

Núñez SeIXas, Xosé Manoel, "Nation-Building and Regional Integration: The Case of the Spanish Empire, 1700-1914”, en Miller y Berger (eds.), 2015, pp. 195-245.

OrtigÃo, Ramalho, Pela terra alheia, Lisboa, 1916, vol. I.

Peralta Ruiz, Víctor, "Emilio Castelar y el hispanoamericanismo del siglo xix", en Tierra Nueva y Cielo Nuevo, 45 (2002), pp. 285-304.

Pérez Vejo, Tomás, "La construcción de las naciones como problema historiográfico: el caso del mundo hispánico", en Historia Mexicana, LIII: 2 (210) (oct.-dic. 2003), pp. 275-311.

Pérez Vejo, Tomás, España en el debate público mexicano, 1836-1867, México, El Colegio de México, 2008.

PéRez Vejo, Tomás, "La hispanofobia como elemento de movilización en las guerras de independencia. ¿Un mito historiográfico"?, en Sánchez Cuervo y Velasco Gómez (coords.), 2012, pp. 219-236.

Pérez Vejo, Tomás, España imaginada. Historia de la invención de una nación, Barcelona, Galaxia Gutenberg, 2015.

Pires, António Manuel Bettencourt Machado, A ideia de decadência na geração de 70, Ponta Delgada, Universidade dos Açores, 1980.

Quental, Antero de, Causas da decadência dos povos peninsulares nos últimos três séculos, Porto, Typ. Commercial, 1871.

Rina Simón, César, "Discursos de alteridad en las Historias Generales de España. La invasión musulmana y la conquista de Granada, 1840-1890”, en Revista de Historiografía, 18 (2013), pp. 124-132.

Rina Simón, César, Iberismos. Expectativas peninsulares en el siglo XIX, Madrid, Funcas, 2016.

RodríGuez, Miguel, Celebración de la raza. Una historia comparativa del 12 de octubre, México, Universidad Iberoamericana, 2004. 
Rodríguez-Esteban, José Antonio, "Geopolitical perspectives in Spain: From the Iberismo of the 19th century to the Hispanoamericanismo of the 20th", en Finisterra, 65 (1998), pp. 185-193.

Sánchez Cuervo, Antolín y Ambrosio Velasco Gómez (coords.), Filosofía politica de las independencias latinoamericanas, Madrid, Biblioteca Nueva, 2012.

Schmidt-Nowara, Christopher y John Nieto-Phillips (eds.), Interpreting Spanish Colonialism: Empires, Nations and Legends, Albuquerque, University of New México Press, 2005.

Sepúlveda, Isidro, "Medio siglo de asociacionismo americanista español (1885-1936)”, en Espacio, Tiempo y Forma., Serie V, Historia Contemporánea, IV (1991), pp. 271-290.

Sepúlveda, Isidro, El sueño de la Madre Patria. Hispanoamericanismo y nacionalismo, Madrid, Marcial Pons, 2005.

Serrano, Carlos, Final del Imperio. España, 1895-1898, Madrid, Siglo Veintiuno editores, 1984.

Serrano, Carlos, El nacimiento de Carmen, Madrid, Taurus, 1999.

SiLmal, Juan Luis, "Una perspectiva atlántica pero la historia española en la Era de las Revoluciones”, en Ayer, 89 (2013), 199-212.

TAPIA, Eugenio, Historia de la civilización española, Madrid, Imp. de Jenes, 1840.

Todorov, Tzvetan, El espiritu de la Ilustración, Barcelona, Galaxia Gutenberg, 2006.

Torgal, Luis Reis, José Amado Mendes y Fernando Catroga, História da História em Portugal. Séculos XIX-XX, Lisboa, Temas e Debates, 1998.

Torres Caicedo, José María, Estudios sobre el gobierno inglés y sobre la influencia anglo-sajona, París, Dramard-Baudry, 1868.

UCelay-Da Cal, Enric, “¿Cómo convertir a los perdedores en ganadores? Un ensayo sobre la proyección finisecular de identidades en los países menos industrializados”, en Morales Moya (coord.), 1998, pp. 164-191.

"Unión Ibero-Americana: estatutos y regla entos", Madrid, Imp. de Moreno y Rojas, 1885. 
Vallerange, Prosper, Le Panlatinisme, Confédération Gallo-Latine et CeltoGauloise, contre-testament de Pierre le Grand et contre-panslavisme, ou Projet d'union fédérative des peuples Gallo-Latins, París, Passard, 1862.

VÁzQuez Cuesta, Pilar, Espanha ante o ultimátum, Lisboa, Livros Horizonte, 1975.

Villaverde Rico, María José y Francisco Castilla Urbano (dirs.), La sombra de la leyenda negra, Madrid, Tecnos, 2016.

Zermeño Padilla, Guillermo, "Historia, experiencia y modernidad en Iberoamérica, 1750-1850", en Anuario de Historia de América Latina, 45 (2008), pp. 113-148. 